\title{
Effect of Direct Compressive Stress on the Shear Transfer Strength of Fibrous Concrete
}

\author{
B. J. Al-Sulayvani \\ J. R. Al-Feel \\ Department of Civil Engineering, College of Engineering, Mosul University
}

\begin{abstract}
Experimental investigation is carried out to study the shear transfer of uncracked fibrous concrete. The test specimens used in this study were of the push-off and modified push-off type .The parameters investigated were the volume fraction of fibers, the amount of stirrups crossing the shear plane, and the ratio of direct to shear stress. Test results showed that the presence of normal stress and fibres increase the first cracking load and shear transfer strength and this enhancement is more pronounced in specimens without stirrups in the shear plane for both push-off and modified push-off specimens. The fibrous specimens showed more stiffness, failed in a ductile mode, and experienced more strain capacity than plain specimens without fibres. From the present test results, a regression analysis was done and a prediction formula is proposed .
\end{abstract}

Keywords: Direct stress; Ductility; Fibrous reinforced concrete; Shear transfer strength; Stirrups.
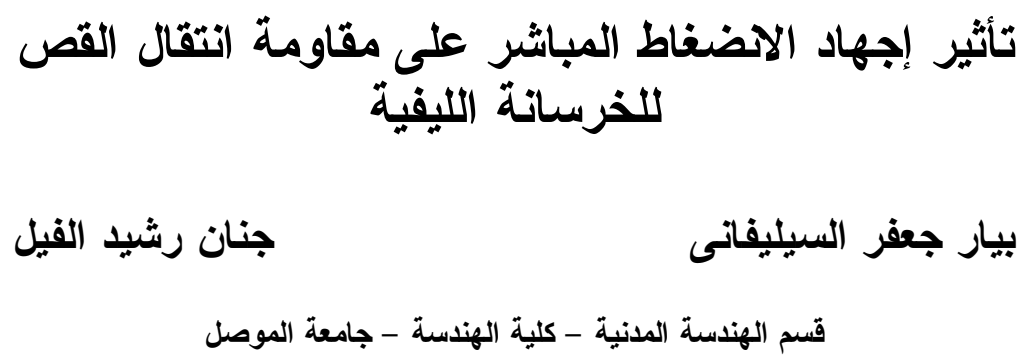

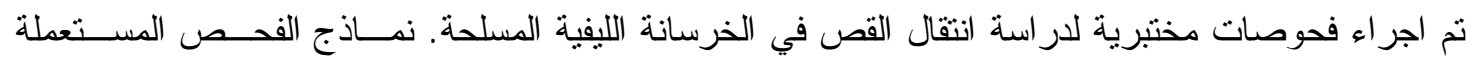

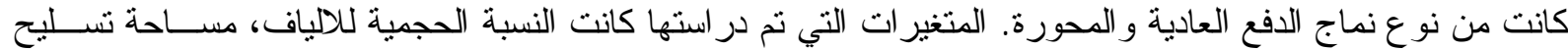
القص التي تقطع مستوي القص ونسبة اجهاد الانضغاط الى اجهاد القص. أظهرت النتائج ان وجود اجهادات التهاد الانضغاط

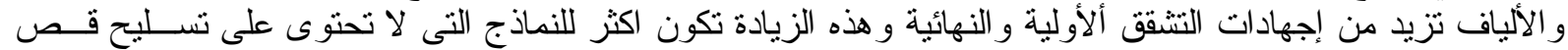

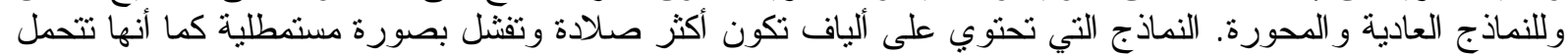
أكثر انفعالات من النماذج بدون الياف النتائج العملية تم تحليلها أحصائيا و اقترحت علئ معادلة لمقاومة القص. 


\section{Introduction}

The shear transfer across specific plane must be considered in design, such as the connection in precast construction, corbels, brackets, ledger beam bearing, and concrete cast at different ages. This problem was studied previously on uncracked and initially cracked normal weight and lightweight concrete by many researchers [1-5]. They have concluded that the shear transfer occurs along either an existing or a potential crack and shear friction equation is developed to predict the shear strength.

The ACI code [6] adopted also the shear friction approach to predict the shear transfer strength of normal and light weight concrete as shown below:

$$
V_{n}=A_{v f} \cdot f_{y} \cdot \mu \quad \leq 0.2 f_{c}^{\prime} \cdot A_{c} \text { nor } 5.5 A_{c}
$$

where $V_{n}=$ nominal shear strength $(\mathrm{MN}), A_{v f}=$ steel area crossing the shear plane, $f_{y}=$ yield strength of steel, and $\mu=$ coefficient of friction which depends on the concrete type and status. Hsu [7] developed a formula to predict the shear transfer strength of reinforced concrete depending on a large amount of previously published test results:

$$
v_{u}=0.822\left(f_{c c}^{\prime}\right)^{0.406}\left(\rho f_{y}\right)^{c}
$$

where $\quad v_{u}=$ unit shear strength $(\mathrm{MPa}), c=0.159\left(f_{c c}^{\prime}\right)^{0.303}, \quad$ and $f_{c c}^{\prime}=$ concrete compressive strength of $150 \mathrm{~mm}$ cube and is taken as $f_{c}^{\prime} / 0.85$.

Steel fibres were used in concrete by Swamy et al. [8] to study their effect on shear transfer. The test results showed that the fibres increase the residual shear transfer strength which was generally lower in lightweight concrete than in normal weight concrete. It was shown also that the shear transfer stiffness can be related to the crack width. Tan and Mansur [9] indicated that the inclusion of fibres significantly improves the strength and deformation characteristics of the concrete. The softened truss model which was used by Hsu et al. [10] for reinforced concrete is also used to predict the strength and deformation response of the tested specimens and showed good agreement.

Khaloo and Kim [11] carried out an experimental investigation to assess the effect of concrete strength on the strength and ductility behaviour of steel fibre reinforced concrete under direct shear. The test results showed that the enhancement in shear strength, toughness, and ductility was more pronounced in high strength concrete than in lower strength concrete. The following formulae were proposed to predict the shear transfer strength of the tested specimens with steel fibres of aspect ratio of 29 and 58 respectively:

$$
\begin{aligned}
& v_{u}=\left(0.65+0.123 v_{f}+0.08 v_{f}^{2}-0.013 v_{f}^{3}\right) \sqrt{f_{c}^{\prime}} \\
& v_{u}=\left(0.65+0.46 v_{f}-0.08 v_{f}^{2}\right) \sqrt{f_{c}^{\prime}}
\end{aligned}
$$

Aziz [12] studied the effect of steel fibres on the shear transfer of plain and reinforced concrete specimens. The results showed that the lateral separation and stirrups strain decrease with the increase of fibres volume fraction and the reinforcement parameter $\rho f_{y}$. 
The study reported in this paper deals with the shear transfer problem across an initially uncracked plane for fibrous concrete by testing push-off and modified push-off specimens to simulate the effect of direct compressive stress on the shear transfer strength. An attempt has been made to develop a prediction equation for shear strength which includes all the parameters which affect the shear transfer.

\section{Experimental Programme}

The parameters investigated included the ratio of the direct compressive to the shear. Tests were done on twelve push-off and twenty-four modified push-off specimens, the details of dimensions and reinforcement are given in Fig. (1). The parameters investigated included the ratio of the direct compressive to the shear stress, transverse shear reinforcement, and fibres volume fraction. Two sizes of stirrups normal to the shear plane were used; 6 and $10 \mathrm{~mm}$ with a yield strength of 510 and $321 \mathrm{MPa}$ respectively. The experimental work consisted of a control mix without fibres and three others with fibres
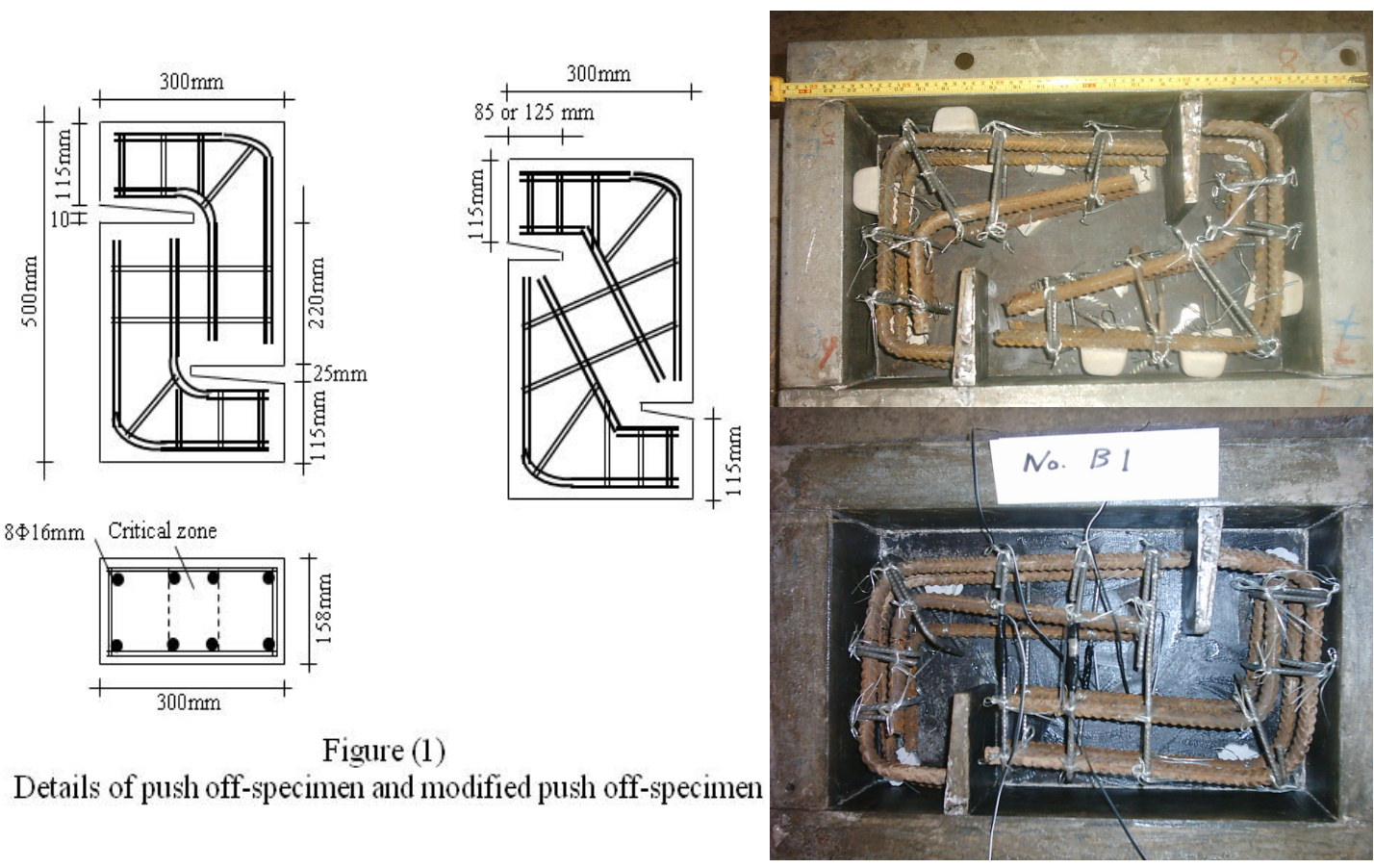

volume fraction of $0.5,1$, and 1.5. A shelled steel fibres were used with a length of $32 \mathrm{~mm}$ and equivalent diameter of $0.97 \mathrm{~mm}$.

Table (1) shows the details of test programme. Ordinary Portland cement, washed natural sand, and $10 \mathrm{~mm}$ coarse aggregates were used throughout the test. The mix proportions used was 1:1.5:2 with water cement ratio of 0.40 . A superplasticizer was used to increase workability with a dose of $450 \mathrm{ml}$ for each $100 \mathrm{~kg}$ of cement as recommended by the manufacturer.

The dry materials were mixed in a horizontal pan mixer, then water with the admixture was added and mixed for 30 seconds. The steel fibres were added gradually by hand and mixed till a good homogeneous mix is obtained. Concrete was poured into the mould in two layers and compacted using a table vibrator. The specimens were left under polythene sheet in laboratory for 24 hours, then demoulded and immersed in water for 14 days and left in the laboratory under polythene sheet until they were tested at 28-days. A control specimens (three $100 \mathrm{~mm}$ cubes for compression and three $100 \mathrm{X} 200 \mathrm{~mm}$ cylinders for splitting test) were cast and cured at the same condition as the push-off specimens. 
The days) and placed on a $150 \mathrm{~mm}$ steel plate and the load was applied through a roller assembly to prevent lateral confinement, Fig. 2.

specimens were tested in a $1000 \mathrm{kN}$ compression machine (at an age of 28-35)

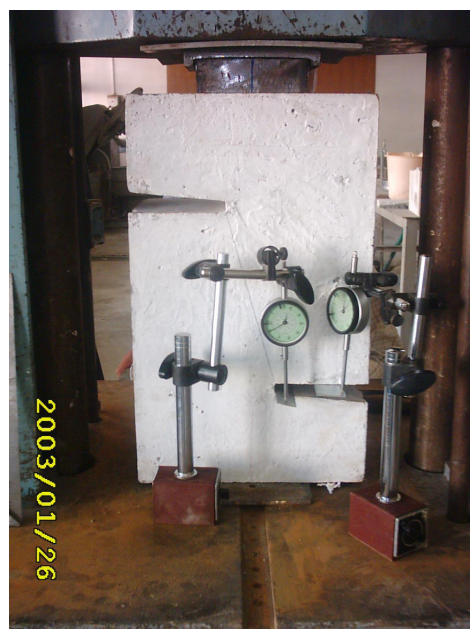

Figure (2) Arrangement of slip measurement

The slip was measured by placing two dial gauges at the upper and lower edge of the lower slot. The concrete strains were measured on the central portion of the critical zone by fixing four pairs of demec points (guage length of $100 \mathrm{~mm}$ ) forming a strain rossette of six readings,. The load was applied incrementally up to failure, and at each load increment the slip and strains were recorded.

\section{Results and Discussion}

\section{Effect of Fibres on Strength}

The cracking and ultimate shear strength of the tested specimens are shown in Figs. 3-5 and Table 1 for different values of $\mathrm{k}$ ( $\mathrm{k}=$ normal stress/shear stress). The results shows that the presence of fibres increases both the cracking and ultimate shear strength. The ratio of cracking to shear strength for the fibrous specimens ranged between $(0.64-1.0),(0.55-0.88)$, and (0.56-0.78) for groups $\mathrm{A}, \mathrm{B}$, and $\mathrm{C}$ respectively. These ratios indicate that the enhancement in strength due to fibres addition is more for specimens with stirrups where the fibres contribution is more mobilized because of the limited cracking due to the presence of stirrups.

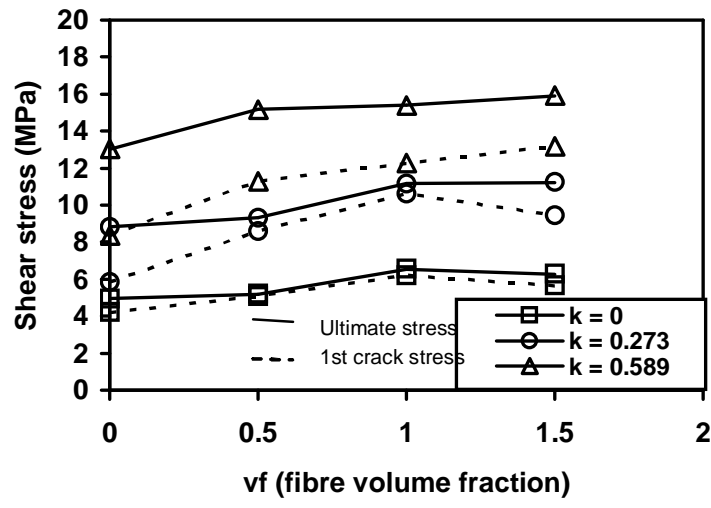

Fig.(3)Variation of first crack and shear strength with the fibre volume fraction $\left(\rho f_{y}=0\right)$

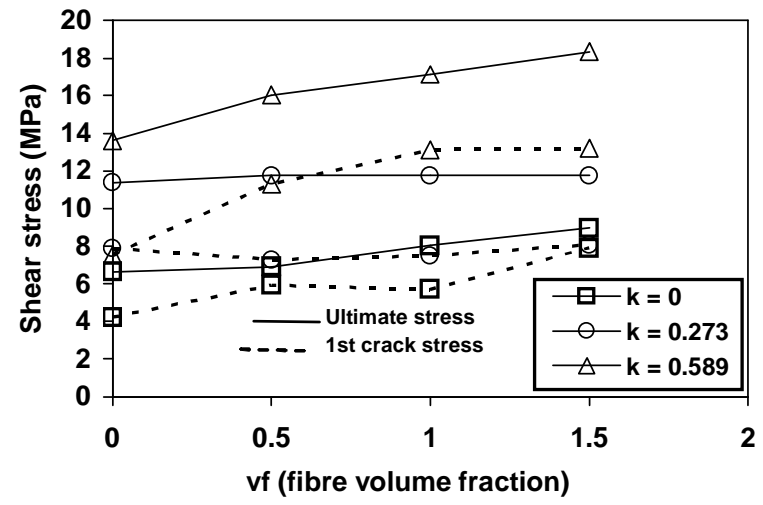

Fig.(4) Variation of first crack and shear strength with the fibre volume fraction $\left(\rho \mathrm{f}_{\mathrm{y}}=2.49\right)$ 
Al-Sulayvani: Effect of Direct Compressive Stress on the Shear Transfer Strength of

Table 1 Detail of the tested specimens and results

\begin{tabular}{|c|c|c|c|c|c|c|c|c|}
\hline $\begin{array}{l}\text { Speci } \\
\text { men } \\
\text { No. }\end{array}$ & $\begin{array}{l}\text { lengt } \\
\mathrm{h} \text { of } \\
\text { shear } \\
\text { plane } \\
\text { mm }\end{array}$ & $\begin{array}{l}\text { Angle } \\
\text { of } \\
\text { inclina } \\
\text {-tion } \\
\text { degree } \\
\text { s }\end{array}$ & $\begin{array}{l}\text { Fibres } \\
\text { volum } \\
\text { e \% }\end{array}$ & $\begin{array}{lr}\text { No. and } \\
\text { dia of } \\
\text { stirrups }\end{array}$ & $\begin{array}{l}\text { Cube } \\
\text { strengt } \\
\text { h MPa }\end{array}$ & $\begin{array}{l}\text { Splittin } \\
\mathrm{g} \\
\text { strength } \\
\mathrm{MPa}\end{array}$ & $\begin{array}{l}\text { Crackin } \\
\text { g } \\
\text { strength } \\
\mathrm{MPa}\end{array}$ & $\begin{array}{l}\text { Shear } \\
\text { strength } \\
\mathrm{MPa}\end{array}$ \\
\hline A1 & 220 & $\overline{0}$ & 0 & $\overline{0}$ & 53.6 & 4.9 & 4.95 & 4.95 \\
\hline $\mathrm{A} 2$ & 230 & 15.25 & 0 & 0 & 54.7 & 4.9 & 5.86 & 8.82 \\
\hline A3 & 256 & 30.50 & 0 & 0 & 54.7 & 4.9 & 8.37 & 13.02 \\
\hline A4 & 220 & 0 & 0.5 & 0 & 55.6 & 5.63 & 5.08 & 5.2 \\
\hline $\mathrm{A} 5$ & 230 & 15.25 & 0.5 & 0 & 56 & 5.63 & 8.6 & 9.32 \\
\hline A6 & 256 & 30.50 & 0.5 & 0 & 56 & 5.52 & 11.3 & 15.17 \\
\hline A7 & 220 & 0 & 1.0 & 0 & 56.3 & 6.56 & 6.21 & 6.55 \\
\hline A8 & 230 & 15.25 & 1.0 & 0 & 56.3 & 6.56 & 10.62 & 11.16 \\
\hline A9 & 256 & 30.50 & 1.0 & 0 & 57.9 & 6.87 & 10.46 & 15.38 \\
\hline A10 & 220 & 0 & 1.5 & 0 & 52.9 & 6.71 & 5.64 & 6.27 \\
\hline A11 & 230 & 15.25 & 1.5 & 0 & 52.9 & 6.8 & 9.45 & 11.23 \\
\hline A12 & 256 & 30.50 & 1.5 & 0 & 51.1 & 6.8 & 13.18 & 15.9 \\
\hline B1 & 220 & 0 & 0 & $3-\varphi 6 \mathrm{~mm}$ & 52.1 & 3.8 & 4.23 & 6.63 \\
\hline $\mathrm{B} 2$ & 230 & 15.25 & 0 & 3- $\varphi 6 \mathrm{~mm}$ & 51.9 & 3.8 & 7.88 & 11.37 \\
\hline B3 & 256 & 30.50 & 0 & 3- $\varphi 6 \mathrm{~mm}$ & 51 & 3.8 & 7.54 & 13.61 \\
\hline B4 & 220 & 0 & 0.5 & 3- $\varphi 6 \mathrm{~mm}$ & 50.9 & 4.43 & 5.93 & 6.9 \\
\hline B5 & 230 & 15.25 & 0.5 & $3-\varphi 6 \mathrm{~mm}$ & 53.3 & 4.43 & 7.29 & 11.75 \\
\hline B6 & 256 & 30.50 & 0.5 & 3- $\varphi 6 \mathrm{~mm}$ & 53.3 & 4.43 & 11.31 & 16.02 \\
\hline B7 & 220 & 0 & 1.0 & 3- $\varphi 6 \mathrm{~mm}$ & 49.4 & 5.31 & 5.7 & 8.04 \\
\hline B8 & 230 & 15.25 & 1.0 & 3- $\varphi 6 \mathrm{~mm}$ & 53.1 & 5.31 & 6.5 & 11.75 \\
\hline B9 & 256 & 30.50 & 1.0 & 3- $\varphi 6 \mathrm{~mm}$ & 53.1 & 5.31 & 13.19 & 17.13 \\
\hline B10 & 220 & 0 & 1.5 & 3- $\varphi 6 \mathrm{~mm}$ & 52.3 & 7.81 & 7.90 & 8.96 \\
\hline B11 & 230 & 15.25 & 1.5 & 3- $\varphi 6 \mathrm{~mm}$ & 51.1 & 7.81 & 8.07 & 11.75 \\
\hline B12 & 256 & 30.50 & 1.5 & 3- $\varphi 6 \mathrm{~mm}$ & 51.1 & 7.81 & 13.19 & 18.34 \\
\hline $\mathrm{C} 1$ & 220 & 0 & 0 & $2-\varphi 10 \mathrm{~mm}$ & 52 & 4.35 & 5.64 & 8.86 \\
\hline $\mathrm{C} 2$ & 230 & 15.25 & 0 & $2-\varphi 10 \mathrm{~mm}$ & 52.9 & 4.35 & 7.29 & 12.63 \\
\hline C3 & 256 & 30.50 & 0 & $2-\varphi 10 \mathrm{~mm}$ & 52.9 & 4.35 & 10.26 & 16.02 \\
\hline $\mathrm{C} 4$ & 220 & 0 & 0.5 & $2-\varphi 10 \mathrm{~mm}$ & 54.2 & 5.03 & 6.2 & 9.47 \\
\hline $\mathrm{C} 5$ & 230 & 15.25 & 0.5 & 2- $\varphi 10 \mathrm{~mm}$ & 53.2 & 5.03 & 7.81 & 12.9 \\
\hline C6 & 256 & 30.50 & 0.5 & 2- $\varphi 10 \mathrm{~mm}$ & 53.2 & 5.03 & 11.09 & 16.40 \\
\hline $\mathrm{C} 7$ & 220 & 0 & 1.0 & $2-\varphi 10 \mathrm{~mm}$ & 48.9 & 5.94 & 6.2 & 9.6 \\
\hline $\mathrm{C} 8$ & 230 & 15.25 & 1.0 & $2-\varphi 10 \mathrm{~mm}$ & 54.2 & 5.94 & 9.12 & 14.58 \\
\hline C9 & 256 & 30.50 & 1.0 & $2-\varphi 10 \mathrm{~mm}$ & 54.2 & 5.94 & 10.26 & 18.40 \\
\hline $\mathrm{C} 10$ & 220 & 0 & 1.5 & 2- $\varphi 10 \mathrm{~mm}$ & 52.2 & 7.31 & 7.9 & 10.10 \\
\hline $\mathrm{C} 11$ & 230 & 15.25 & 1.5 & 2- $\varphi 10 \mathrm{~mm}$ & 53.3 & 7.31 & 10.68 & 14.72 \\
\hline $\mathrm{C} 12$ & 256 & 30.50 & 1.5 & $2-\varphi 10 \mathrm{~mm}$ & 53.3 & 7.31 & 12.14 & 19.18 \\
\hline
\end{tabular}




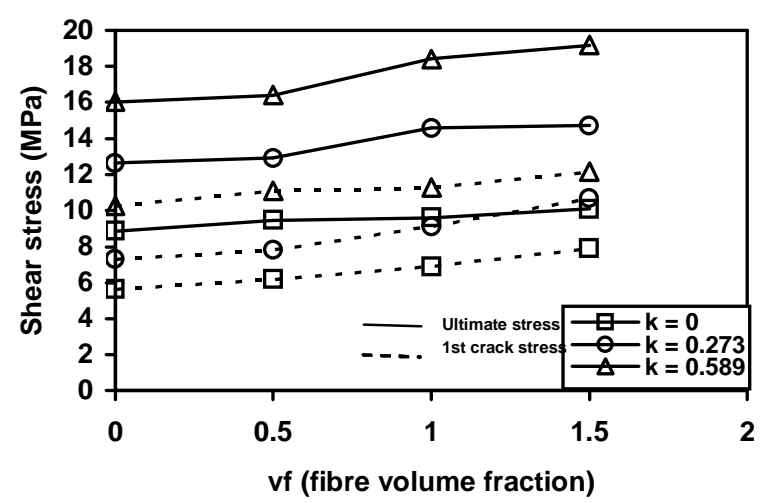

Fig.(5) Variation of first crack and shear strength with the fibre volume fraction $\left(\rho f_{y}=3.38\right)$

\section{Effect of Compressive Stress}

Due to the inclined shear plane a compressive stress will be induced normal to shear plane. Figs. 6-8 show that the shear strength increases approximately linear with the direct compressive stress for all fibres content and reinforcement parameter $\rho f y$. It was shown also that the lateral compressive stress increase the difference between the cracking and ultimate strength, since the former will decrease the diagonal tensile stresses developed by shear.

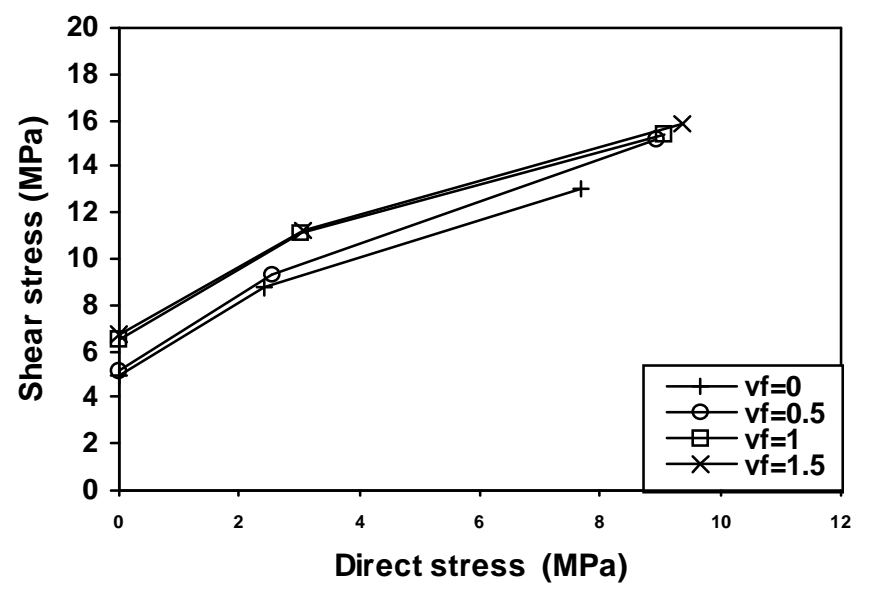

Fig. ( 6 )Variation of the shear strength with the direct stress $\left(\rho f_{y}=0\right)$

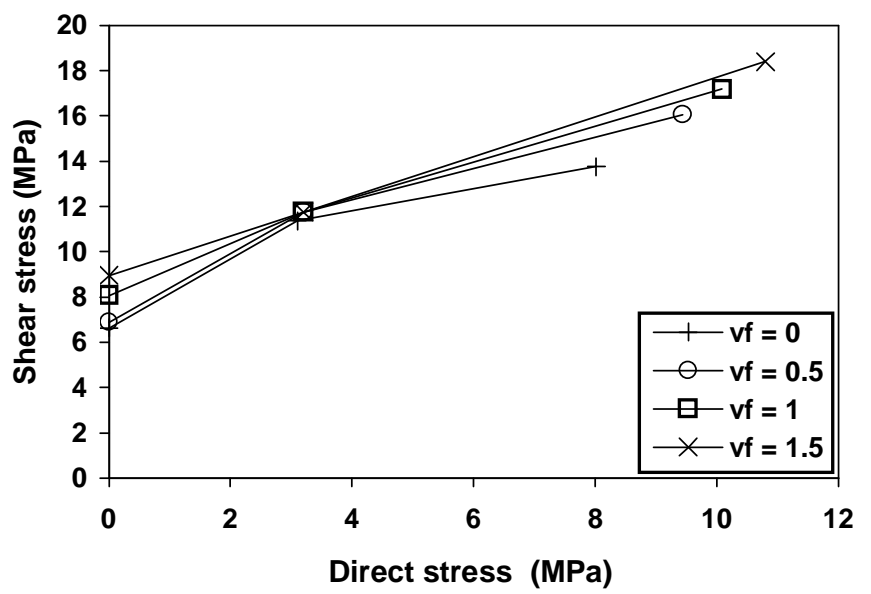

Fig. (7) Variation of the shear strength with the direct stress $\left(\rho f_{y=2.49}\right)$ 


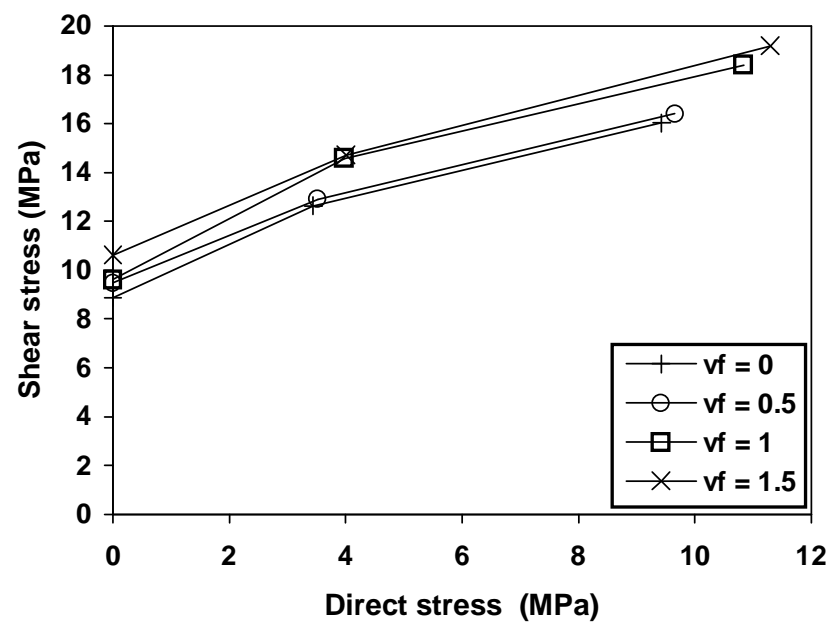

Fig. (8) Variation of the shear strength with the direct stress $\left(\rho f_{y}=3.38\right)$

\section{Effect of Reinforcement Parameter}

The effect of the reinforcement parameter $\rho$ fy on the shear strength is shown in Figs. 9-11. The figures show that the shear strength increases with the reinforcement parameter as demonstrated by previous authors for normal and fibrous concrete [1-12]. Table 1 and Figs. 911 shows that a fibres volume of 1-1.5 percent could give a strength equivalent to a reinforcement parameter of 2.49-2.92 $\mathrm{MPa}$ for all values of the direct stress.

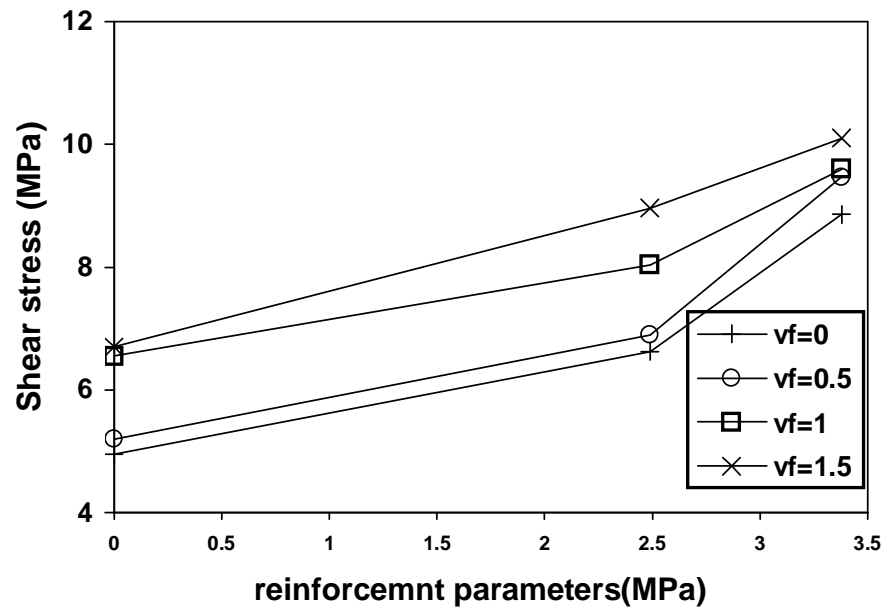

Fig.(9) Variation of shear strength with reinforcement parameters $(\mathrm{k}=0)$

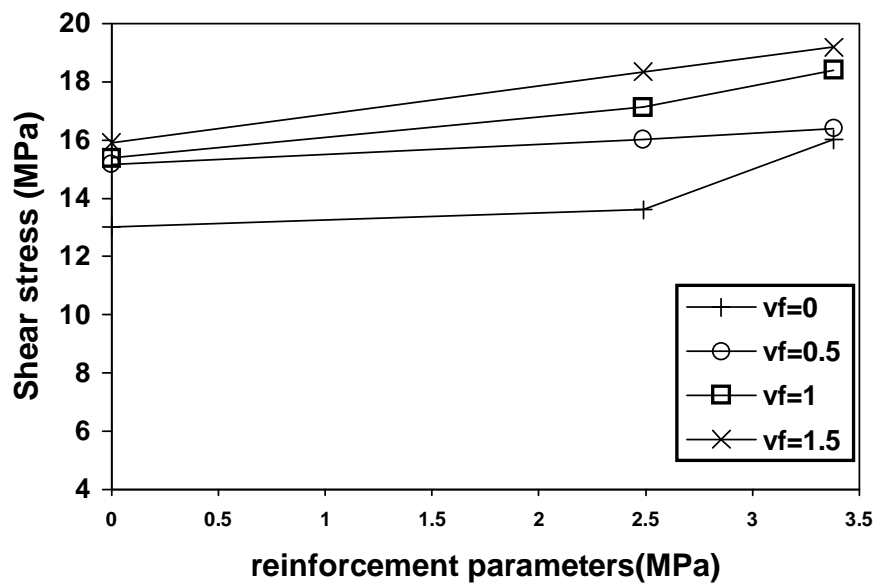

Fig.(10) Variation of shear strength with reinforcement parameters $(k=0.589)$ 


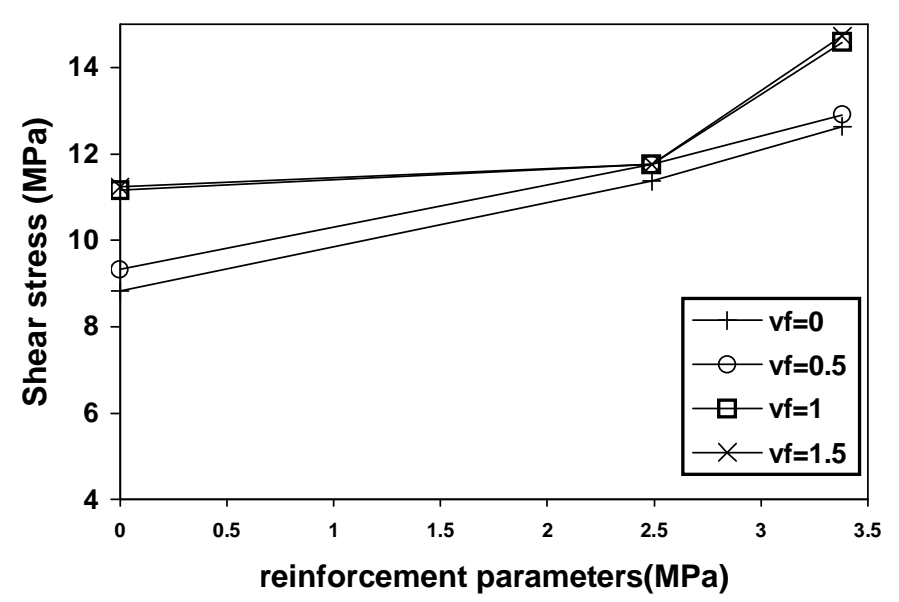

Fig.(11) Variation of shear strength with reinforcement parameter $(\mathrm{k}=0.273)$

\section{Deformation Characteristics}

From the large amount of experimental test results of concrete strains and slip only typical results will be presented for brevity. The slip and strains measurements could not be followed up to the failure loads and in most cases it was stopped one or two increments before failure.

\section{Principal Strains}

Fig. 12 shows the shear stress versus the principal concrete strains for specimens B3, B6, $\mathrm{B} 9$, and $\mathrm{B} 12$ (with a ratio of compressive to shear stress $\mathrm{k}=0.589$ ), with fibres percentages of $0,0.5,1.0$, and 1.5 respectively, and with three stirrups $6 \mathrm{~mm}$ in diameter. The Figure shows that the fibrous specimens have smaller compressive and tensile strains at early loads, i.e.; shows more stiffness and at ultimate stages have more strain capacity.

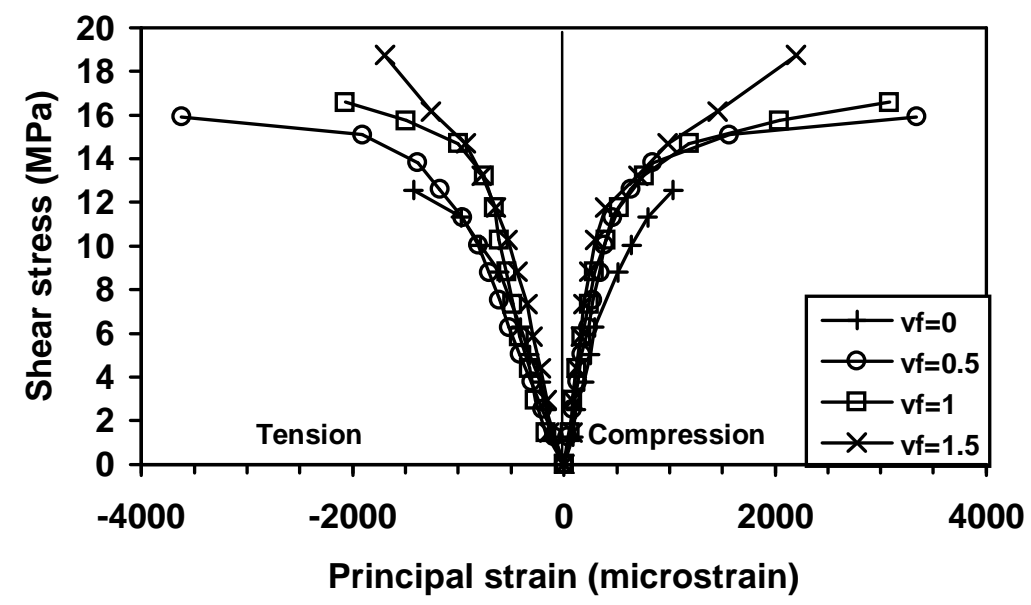

Fig.(12) Shear stress-principal strain for B3,6,9,12

\section{Shear Strain}

Fig. 13 shows the shear stress versus the maximum shear strain for specimens A2, A5, A8, and A11 (with a ratio of compressive to shear stress $\mathrm{k}=0.273$ ), with fibres percentages of 0 , $0.5,1.0$, and 1.5 respectively and without shear reinforcement. The Figure shows that the fibrous specimens have smaller shear strains at early loads, i.e.; higher rigidity modulus and at ultimate loads have more strain capacity. 


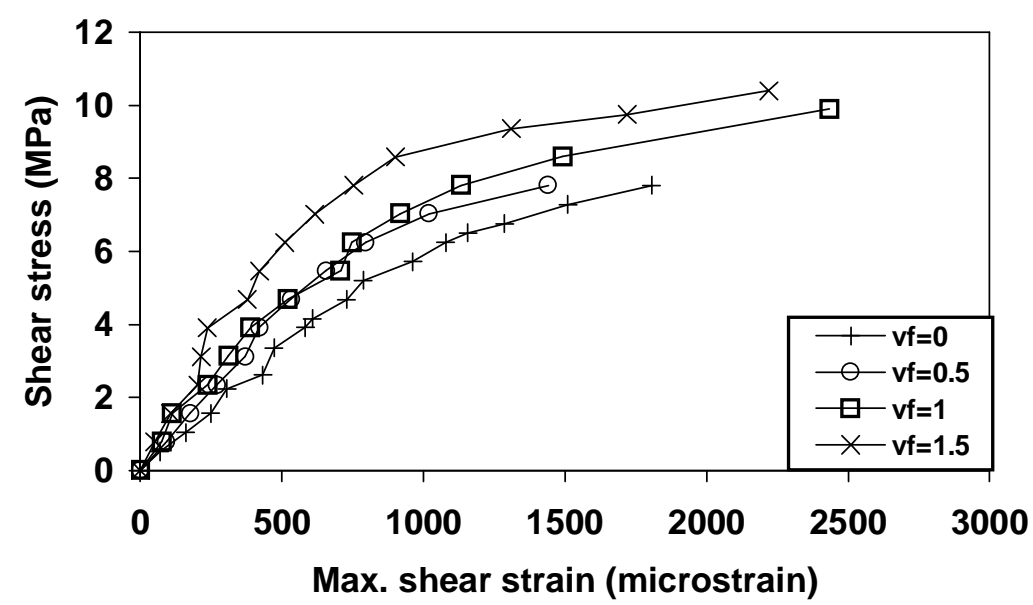

\section{Slip}

Fig.(13) Shear stress-maximum shear strain A2,5,8,11

Figs. 14-16 show the variation of the slip with the shear stress for specimens A3, B3, and C3 with $\rho$ fy of $0,2.17$, and 2.85 respectively and with a ratio of compressive to shear stress $\mathrm{k}=0.589$. The figures show that the presence of fibres decrease the slip at the early stages of loading; i.e.; increased the stiffness, and at ultimate stages the specimens experienced a ductile behaviour for the three reinforcement parameters.

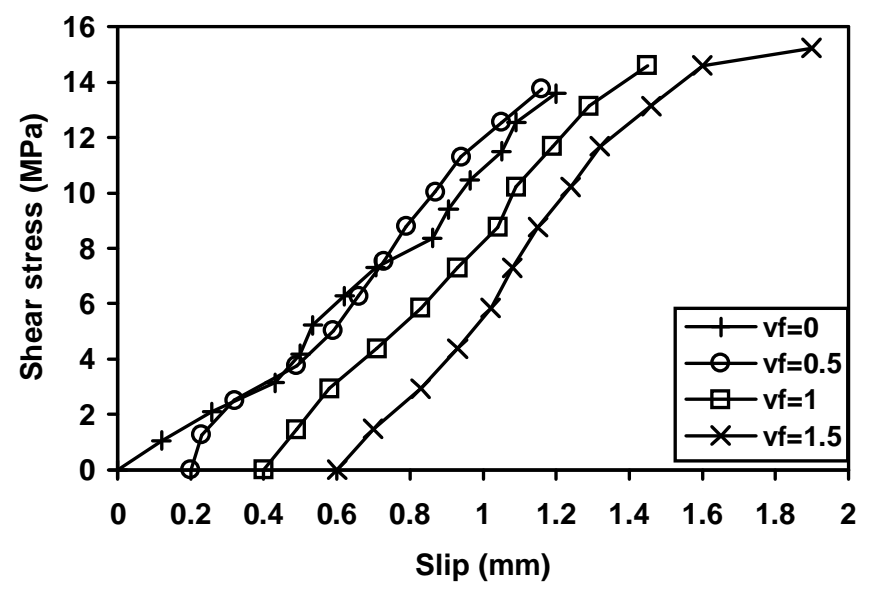

Fig.(14) Variation of slip with shear stress (A3)

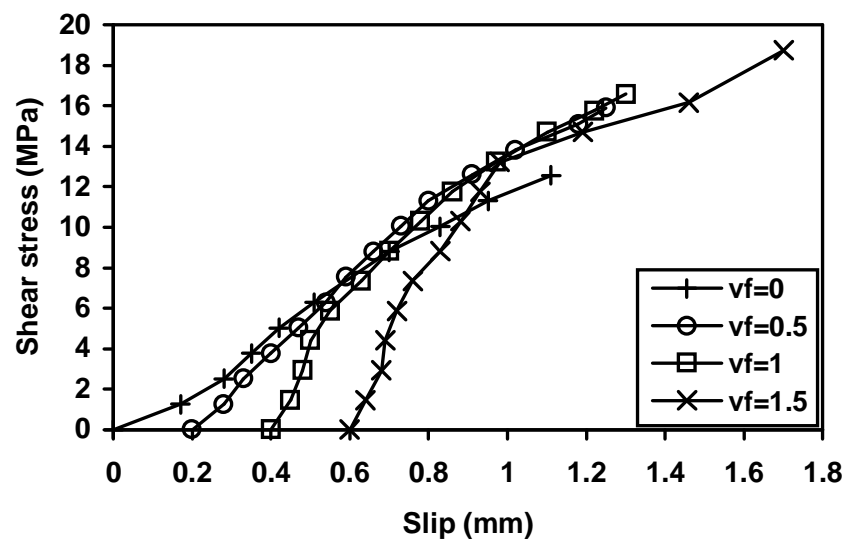

Fig.(15) Variation of slip with shear stress (B3) 


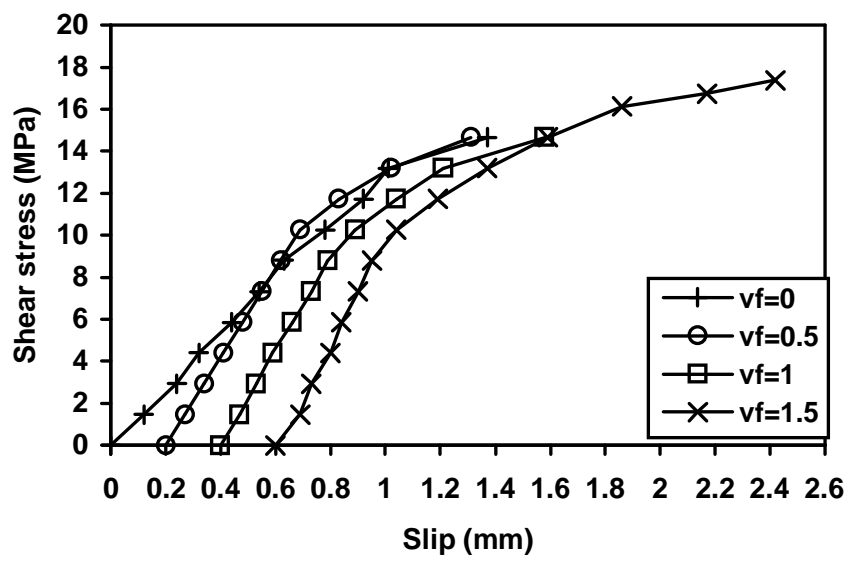

Fig.(16) Variation of slip with shear stress (C3)

\section{Mode of failure}

As the load was applied gradually the shear cracks appear near the upper and lower slots and with increasing loads the cracks were propagating toward the centre of the specimens. Fig. 17 shows the failed specimens A10, A11, and A12 without shear reinforcement but with fibres percentage of 1.5. The figure shows how the specimens retained their integrity at failure, while those without fibres spitted into two parts as the ultimate load was attained. Fig. 18 shows also the failed specimens B7, B8, and B9 with shear reinforcement and one percent steel fibres. The figure shows that the cracks at failure were narrower than those in Fig. 17 where there was no shear reinforcement.

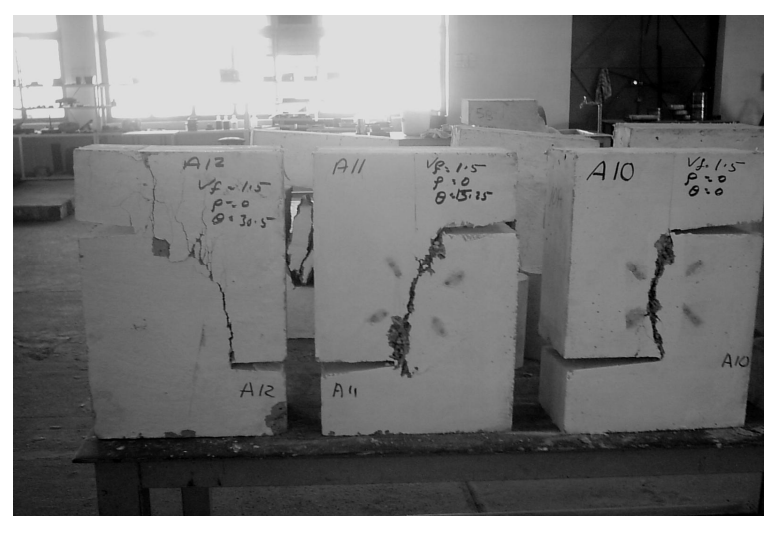

Fig.(17) Mode of failure for $\mathrm{A}(10,11$, and 12$)$

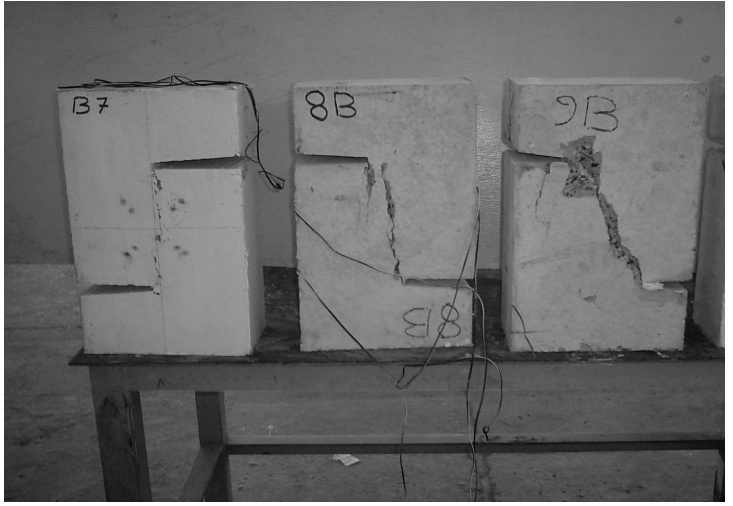

Fig.(18) Mode of failure for $\mathrm{B}(7,8$, and 9)

\section{Linear Regression Analysis}

A linear regression analysis was used for the test results of this study [13] to identify the importance of the independent variables such as, the concrete strength, reinforcement parameter, transverse compressive stress, and the steel fibres. Since shear failure is initiated by diagonal cracks, the later is limited to the tensile strength of concrete which in turn related to $\sqrt{f_{c}^{\prime}}$ and is used in the analysis; the following equation was obtained:

$v_{u}=0.87 \sqrt{f_{c}^{\prime}}+0.87 \rho f_{y}+0.9 \sigma_{n}+3.3 v_{f} l_{f} / d_{f}$

The cylinder strength assumed equal to 0.8 times the cube strength. The contribution of the reinforcement to the shear strength in Eq.5 approximately equal to that derived be Swamy et al. [8] for fibrous concrete. The second and third multiplier in Eq.5 are slightly less than that derived by Mattock et al.[3,5] for normal reinforced concrete. The correlation coefficient (R) of Equation (5) was 0.997. 
The analysis of the results revealed that the standardized coefficient $\beta$ which reflect the importance of the independent variables showed that $\sqrt{f_{c}^{\prime}}$ was the most important one followed by the transverse compression stress, reinforcement parameter, and the steel fibres.

\section{Conclusions}

1. The addition of steel fibres to concrete increase the first crack strength and shear transfer strength of concrete.

2. The simultaneous action of the direct compressive stress with the direct shear increase the shear strength considerably.

3. The presence of steel fibres decrease the strains and slips in the early stages of loading and increase the strain capacity prior to failure that leads to a ductile mode of failure.

4. The proposed equation for the shear transfer strength yield a reliable and conservative estimate of the shear strength of the tested samples in the present study.

5. More test results may lead to a more comprehension of the steel fibres role in enhancing strength and controlling the deformation and refinement of the proposed equation.

\section{References}

[1] Hofbeck J.A, Ibrahim, I.O., Mattock, A.H. ,Shear transfer in reinforced concrete. ACI J Proc;Vol.66, No. 2, 1969, pp. 119-128.

[2] Mattock, A.H., Hawkins N.M., Shear transfer in reinforced concrete. PCI Jour. Proc, Vol.17,NO.2, 1972, PP. 55-75.

[3] Mattock, A.H. ,Shear transfer in concrete having reinforcement at an angle to the shear plane. ACI ,SP-42, 1974, PP. 17-42.

[4] Mattock, A.H., Johal, L. and Chow, H.C. ,Shear transfer in reinforced concrete with moment or tension acting across the shear plane. PCI Journ.Vol. 20, No. 4, 1975,PP.7793.

[5] Mattock, A.H., Li, W.K., and Wang, T.C. ,Shear transfer in lightweight reinforced concrete. PCI Journ.,Vol.21,No.1, 1976, pp. 21-38.

[6] ACI Committee 318. Building code requirements for reinforced concrete (ACI 318 -02) Detroit: American Concrete Institute;2002

[7] Hsu, T.T.C., Unified approach to shear analysis and design . Cement and Concrete Composites, Vol.20, No.8, 1998, pp.419-435.

[8] Swamy, R.N., Jones, R., and Chiam, T. Shear transfer in steel fiber reinforced concrete. ACI, SP-105-,1989, pp. 565-592.

[9] Tan, K.H., Mansur, M.A., Shear transfer in reinforced fiber concrete, Journal of Materials in Civil Engg. ASCE, Vol.2, No.4,1990, pp.202-213.

[10] Hsu, T.T.C., Mau, S.T., and Chen, B. ,Theory of shear transfer strength of reinforced concrete. ACI Journ. Proc.Vol.9, No.1, 1987, pp.149-160.

[11] Khaloo, A.R., Kim, N. Influence of concrete and fiber characteristics on behaviour of steel fiber reinforced concrete under direct shear. ACI Materials Journ. Vol.94,No.6,1997, pp. 592-601.

[12] Aziz, E.M. Direct Shear strength of fiber reinforced concrete. M.Sc. Thesis, Tikrit University 2000;108.

[13] AL-Feel, J.,R., Experimental and Numerical Investigation of Shear Transfer with Direct Stress in Steel Fibre Reinforced Concrete, Ph .D. Thesis, Civil Engg. Department, University of Mosul, 2006 ,pp. 219.

The work was carried out at the college of Engg. University of Mosul 